\title{
Interactions of new lactoglobulin variants with tetracaine: crystallographic studies of ligand binding to lactoglobulin mutants possessing single substitution in the binding pocket*
}

\author{
Joanna I. Loch ${ }^{1 凶}$, Piotr Bonarek², Monika Siuda', Paulina Wróbel ${ }^{1}$ and Krzysztof Lewiński ${ }^{1}$ \\ 1Department of Crystal Chemistry and Crystal Physics, Faculty of Chemistry, Jagiellonian University, Kraków, Poland; 2Department of Physical \\ Biochemistry, Faculty of Biochemistry, Biophysics and Biotechnology, Jagiellonian University, Kraków, Poland
}

\begin{abstract}
$\beta$-Lactoglobulin (BLG) like other lipocalins can be modified by mutagenesis to re-direct its ligand binding properties. Local site-directed mutagenesis was used to change the geometry of the BLG ligand binding pocket and therefore change BLG ligand preferences. The presented studies are focused on previously described mutants L39Y, I56F, L58F, F105L, and M107L and two new BLG variants, L39K and F105A, and their interactions with local anesthetic drug tetracaine. Binding of tetracaine to BLG mutants was investigated by X-ray crystallography. Structural analysis revealed that for tetracaine binding, the shape of the binding pocket seems to be a more important factor than the substitutions influencing the number of interactions. Analyzed BLG mutants can be classified according to their binding properties to variants: capable of binding tetracaine in the $\beta$-barrel (L58F, M107L); capable of accommodating tetracaine on the protein surface $(\mathrm{I56F})$ and unable to bind tetracaine (F105L). Variants L39K, L39Y, and F105A, had a binding pocket blocked by endogenous fatty acids. The new tetracaine binding site was found in the I56F variant. The site localized on the surface near Arg124 and Trp19 was previously predicted by in silico studies and was confirmed in the crystal structure.
\end{abstract}

Keywords: lactoglobulin, mutation, tetracaine, surface binding site, crystal structure, $\beta$-barrel

Received: 15 January, 2021; revised: 16 February, 2021; accepted: 16 February, 2021; available on-line: 15 March, 2021

$\square$ e-mail: loch@chemia.uj.edu.pl, joanna.loch@uj.edu.pl

*Dedication: This article is dedicated to Prof. Wladek Minor. Best wishes on your $75^{\text {th }}$ birthday, Wladek! Taking advantage of this occasion, J. Loch and M. Siuda wish cordially to thank Wladek Minor for the invitation to the Wladek Minor's Laboratory at University of Virginia (2016-2018) and the opportunity to work with excellent Researchers, possibility to gain important scientific experience and many wonderful memories from visiting the city of Charlottesville. PDB accession numbers: 7BGZ, 7BH0,7BF8, 7BF7, 7BGX, 7BGA, 7BF9

Acknowledgments of Financial Support: Studies were supported by the Polish National Science Centre (NCN), Grant Number: 2012/05/B/ST5/00278.

Abbreviations: BLG, $\beta$-lactoglobulin; TET, tetracaine

\section{INTRODUCTION}

$\beta$-Lactoglobulin (BLG), a small globular protein belonging to a lipocalin family, like other lipocalins can be modified by mutagenesis to re-direct its ligand binding specificity (Deuschle et al., 2020). Human lipocalins are usually modified by randomization of flexible loops surrounding $\beta$-barrel to create highly specific proteins with potential medical applications called Anticalins (Rothe \& Skerra, 2018). In our studies, local site-directed mutagenesis was used to change the geometry of the BLG ligand binding pocket and therefore change its ligand preferences (Loch et al., 2018; Bonarek et al., 2020). Detailed physicochemical characteristics of seven new lactoglobulin mutants (L39Y, I56F, L58F, V92F, V92Y, F105L, and M107L) as well as crystal structure of five of these variants and their complexes with selected fatty acids have been published elsewhere (Bonarek et al., 2020). Crystallographic investigations revealed significant changes of the binding pocket shape in two mutants, I56F and F105L. In both variants, the binding site was shorter than in the wild-type (WT) protein. The presence of a rigid aromatic ring introduced at position 56 prevented the binding of fatty acids by I56F variant, while in F105L variant the binding ability was retained due to the higher flexibility of the binding pocket (Bonarek et al., 2020). Interestingly, fatty acid bound by F105L variant had unusual bent conformation, not observed previously in any other lactoglobulin structures, indicating adjustment of both binding pocket and ligand conformation. Variants L39Y, L58F and M107L retained the elongated shape of the binding pocket, very similar to the one present in WT protein. Their ability to bind fatty acids was confirmed by crystal structures revealing the presence of a single fatty acid molecule bound in an extended conformation in the $\beta$-barrel (Bonarek et al., 2020).

Fatty acids are considered to be the natural ligands of lactoglobulin, so their interactions with modified BLG were investigated first. However, in the course of our systematic studies (Loch et al., 2011; Loch et al., 2012; Loch et al., 2013b; Loch et al., 2013a; Loch et al., 2014; Loch et al., 2015b) aimed to investigate the binding of different ligands to natural lactoglobulin isolated from cow, goat, and sheep milk, we showed that derivatives of fatty acids and the model drug, tetracaine (TET), can also be accepted by the binding pocket. Tetracaine, a model amphiphilic ligand possessing an elongated structure with two short aliphatic fragments and an aromatic ring, is classified as a local anesthetic drug. Tetracaine binds to natural bovine BLG with an affinity lower than fatty acids (Loch et al., 2015a). Crystal structures revealed that TET is bound in the BLG $\beta$-barrel in the same way as fatty acids, even though it has a bulky aromatic ring in its structure and is less flexible than aliphatic compounds.

The studies presented here are a continuation and extension of our previous work aimed to fully characterize new lactoglobulin mutants with a binding pocket modified by a single mutation (Bonarek et al., 2020). This re- 


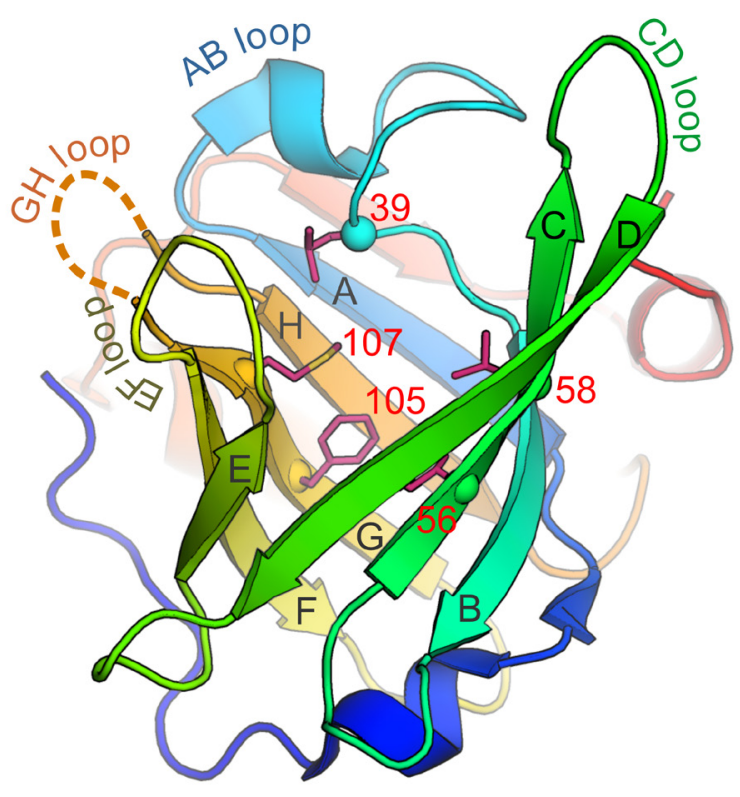

Figure 1. WT BLG molecule (PDB ID: 6QI6) with marked flexible loops $(A B, C D, E F, G H), \beta$-strands $A-H$ and mutation sites: 39 (L39K, L39Y), 56 (I56F), 58 (L58F), 105 (F105A, F105L) and 107 (M107L).

port is focused on previously described mutants L39Y, I56F, L58F, F105L, and M107L (Bonarek et al., 2020) and two new variants, L39K and F105A (Fig. 1). The L39K mutant was created to enhance positive charge at the entrance to the binding pocket in close proximity to two other lysines. It can be considered as an alternative to the L39Y which had increased thermal stability, but its binding site was permanently blocked by an endogenous fatty acid. The second variant, F105A was designed to enlarge the binding pocket which in previously characterized variant F105L was shortened but could accommodate aliphatic ligand in a bent conformation.

Ligand binding by lactoglobulin, although quite specific and selective, is in most cases entropically-driven (Loch et al., 2011; Loch et al., 2012; Loch et al., 2013a; Loch et al., 2015a). The simplest method to determine ligand affinity is the use of ITC, which is time-consuming. In our previous studies, we noticed that crystallization of BLG-ligand complexes usually corresponds well to the ITC results, so these two approaches are almost equally useful for assessing the ligand binding properties of lactoglobulin (Loch et al., 2012; Loch et al., 2013a; Loch et al., 2013b; Loch et al., 2015a). Since the crystallization of BLG-ligand complexes is relatively fast, inexpensive, and reproducible, crystallographic studies were used here as the primary approach to probing the TET binding ability of new BLG mutants.

\section{METHODS}

\section{Protein expression and purification}

All lactoglobulin mutants presented in this report were produced in E.coli Origami B (DE3) strain using coexpression with DsbC according to the previously published protocol (Loch et al., 2016). Proteins were purified using $50 \mathrm{mM}$ phosphate buffer $\mathrm{pH} 6.5$ and a two-step chromatographic procedure described elsewhere (Loch et al., 2016). Protein purity and homogeneity were checked by SDS-PAGE. Prior to crystallization, BLG mutants were concentrated using Amicon $10 \mathrm{kDa}$ spin columns. Protein concentration was determined spectrophotometrically at $280 \mathrm{~nm}$ using molecular weight and absorption coefficient calculated individually for each variant with the use of ProtParam server (Gasteiger et al., 2005).

\section{Protein crystallization}

Proteins were co-crystallized with tetracaine using the vapor diffusion method in hanging drop setup. In order to identify conditions producing the best quality crystals, each mutant was crystallized using solutions containing $\left(\mathrm{NH}_{4}\right)_{2} \mathrm{SO}_{4}$ in the range from 2.0 to $3.0 \mathrm{M}$ (in $0.5 \mathrm{M}$ Tris$\mathrm{HCl} \mathrm{pH}$ from 7.1, 8.0, or 8.5). Drops were set manually by mixing $2 \mu \mathrm{l}$ of protein (usually about $20-24 \mathrm{mg} / \mathrm{ml}$ ), $2 \mu \mathrm{l}$ of the well solution, and $0.5 \mu \mathrm{l}$ of $10 \mathrm{mM}$ tetracaine hydrochloride dissolved in water (Table S1 at https:// ojs.ptbioch.edu.pl/index.php/abp/). Such composition of drop corresponds approximately to BLG:TET molar ratio of 1:2. The use of higher tetracaine concentration was not possible due to its strong precipitation in the crystallization drop. Crystals usually grew in $24-48 \mathrm{~h}$, in some cases further optimization was required, especially if ammonium sulfate solutions did not produce highquality crystals. In this case, $1.34 \mathrm{M}$ sodium citrate was used as an alternative precipitant. The same procedure was used to crystalize unliganded L39K and F105A. Detailed crystallization conditions are listed in Table S1 at https://ojs.ptbioch.edu.pl/index.php/abp/.

\section{$X$-ray data collection and structure determination}

X-ray diffraction data were collected at SuperNova and XtaLAB Synergy-S diffractometers (Rigaku Oxford Diffraction) at $100 \mathrm{~K}$ using $\mathrm{CuK} \alpha$ radiation. Crystals were cryoprotected using a mixture of glycerol and ethylene glycol added to the appropriate crystallization solution. X-ray diffraction data were processed using Crys Alis software (Rigaku Oxford Diffraction) and Aimless from the CCP4 package (Winn et al., 2011). Structures were solved by molecular replacement in Phaser (McCoy et al., 2007) and refined in Refmac5 (Murshudov et al., 2011). Electron density maps were investigated in Coot (Emsley et al., 2010). Statistics of data collection and structure refinement are summarized in Table S2 at https://ojs.ptbioch. edu.pl/index.php/abp/. Structures were deposited in the Protein Data Bank as entries: 7BGZ, 7BH0, 7BF8, 7BF7, 7BGX, 7BGA, and 7BF9 (Table S2 at https://ojs. ptbioch.edu.pl/index.php/abp/).

\section{Circular dichroism}

Circular dichroism (CD) spectroscopy was used to determine the secondary and tertiary structure of L39K and F105A. CD spectra were recorded on a Jasco J-710 instrument using cells of $5 \mathrm{~mm}$ and $200 \mu \mathrm{m}$ path length for near-UV and far-UV measurements, respectively. Protein concentrations in the range of $20-86 \mu \mathrm{M}$ were used for measurements. Each spectrum was obtained from an average of three scans. Spectra were corrected for $50 \mathrm{mM}$ phosphate buffer $\mathrm{pH} 6.5$ contribution and normalized to the peptide bond concentration for farUV and the protein concentration for near-UV. The secondary structure composition was estimated using CDPro spectra deconvolution software using the CONTINLL algorithm and the SDP42 reference spectra data set (Sreerama \& Woody, 2000). Recorded CD spectra are presented in Fig. S1 at https://ojs.ptbioch.edu.pl/index. php/abp/. 


\section{RESULTS AND DISCUSSION}

\section{Structure of L39K and F105A mutants}

Circular dichroism (CD) spectroscopy was used to determine the secondary and tertiary structure of F105A and $\mathrm{L} 39 \mathrm{~K}$ variants. The CD spectra of both variants were consistent with the results previously obtained for the WT protein and other BLG variants (Bonarek et al., 2020). The $\alpha$-helical structure contents were $16 \%$ and $3 \%$ and the $\beta$-sheet contents were $34 \%$ and $37 \%$ for F105A and L39K, respectively. The hypsochromic broadening of the minimum at about $210 \mathrm{~nm}$ in the farUV region for L39K results from a lower content of the secondary structure. In the near-UV spectrum region $(240-350 \mathrm{~nm})$ the typical positions of all the extremes observed for WT lactoglobulin are preserved, in particular the minima at 293 and $286 \mathrm{~nm}$, which only changed the intensity. The exchange of phenylalanine to alanine at position 105 did not affect the CD measurements.

Both new variants, L39K and F105A, crystallized in the trigonal space group $\mathrm{P}_{2} 21$ with a single protein chain in the asymmetric unit. This is the symmetry commonly observed for crystals of either natural or recombinant $\beta$-lactoglobulin (Loch et al., 2012; Bonarek et al., 2020) The conformation of the main chain is very similar to WT protein (PDB ID: 6QI6), with r.m.s deviation for $\mathrm{C} \alpha$ superposition equal to $0.21 \AA(\mathrm{F} 105 \mathrm{~A})$ and 0.22 $\AA$ (L39K). In both structures, the GH loop is partially disordered. In F105A, EF loop has open conformation that is similar to the one observed in the WT protein (r.m.s.d. $0.71 \AA$ ).

In the F105A mutant, Ala105 is located at rigid $\beta$-strand $F$, not susceptible to movement and its relatively short side chain significantly enlarges the central part of the binding pocket (Fig. S2 at https://ojs.ptbioch.edu. $\mathrm{pl} /$ index.php/abp/) without affecting the position of surrounding residues. Although the F105A variant was crystallized without any ligand addition, a strong elongated electron density was visible in the modified binding pocket, indicating the presence of a small molecule interpreted as endogenous fatty acid originating from the expression host. Therefore, F105A is another example of a BLG variant with the binding pocket permanently blocked by an endogenous fatty acid molecule (Bonarek et al., 2020).

The ligand hydrocarbon chain is bent in the region of F105A substitution and its end is located near the bottom of the binding pocket. The conformation of the fatty acid differs from that observed in structures of unmodified protein or bent conformation of myristic acid in the F105L structure (Fig. S2 at https://ojs.ptbioch. edu.pl/index.php/abp/). Such a conformation allows additional hydrophobic contacts in the enlarged binding pocket, which appear to be necessary for stabilization of the protein molecule. In the F105L variant, the bent ligand conformation resulted from the shorter length of the binding pocket and its enlargement in the direction of the AB loop (Fig. S2 at https://ojs.ptbioch.edu.pl/index.php/abp/).

A similar tendency to retain endogenous fatty acid in the modified binding pocket was observed for L39Y (Bonarek et al., 2020) and L39K variants. Crystallization of the L39K in the presence or absence of ligand always resulted in a structure showing elongated electron density in the binding pocket (Fig. S3 at https://ojs.ptbioch. edu.pl/index.php/abp/). Although this density was a little shorter than that observed in F105A or L39Y struc- tures, it also indicated the presence of endogenous fatty acid bound in the $\beta$-barrel. The binding site of the L39K variant retained its elongated shape very similar to that observed in the WT protein (Fig. S3 at https://ojs.ptbioch.edu.pl/index.php/abp/). The Lys39 side chain is located in the space between $\mathrm{AB}$ and $\mathrm{GH}$ loops without affecting the conformation of neighboring residues and is directed towards the Ser116 carbonyl oxygen. It interacts neither with the ligand nor with other protein residues.

In our previous study, it was noticed that the L39Y variant had increased thermal stability and expression yield. It was probably the results of the increased number of hydrophobic contacts made by Tyr39 and the presence of endogenous fatty acid in the $\beta$-barrel (Bonarek et al., 2020). On the contrary, L39K was expressed with a very low efficiency and its CD spectra show decreased content of secondary structure indicating partial unfolding of protein (Fig. S1 at https://ojs.ptbioch.edu. $\mathrm{pl} /$ index.php/abp/). Also, crystals of L39K mutant diffracted X-rays to $2.40 \AA$ only, while for other variants maximum resolution was in the range $2.1-1.8 \AA$. This indicates that the introduction of positively charged Lys at position 39 destabilized the BLG structure possibly by preventing its interactions with adjacent residues.

\section{Tetracaine binding in the crystalline phase}

$\mathrm{X}$-ray crystallography is a method that not only identifies ligands bound to protein but also shows how ligand binds and provides information on the protein function, dynamics, oligomeric state, and interactions between macromolecules (Keedy et al., 2018). Such a complete set of data coming from a single experiment is difficult to obtain by other methods. The ligand binding by BLG is in most cases based on nonspecific hydrophobic interactions and is entropy driven. Therefore, the most appropriate method of monitoring the affinity of lactoglobulin to ligand is ITC, usually combined with the determination of the crystal structure of the protein-ligand complex. Our previous studies showed that the crystallization of BLG-ligand complexes usually corresponds well to the ITC detection of complex formation. Therefore, only X-ray crystallography was used in this work to monitor the binding of tetracaine to BLG. Crystallization of BLG and its mutants is usually very fast, reproducible and the obtained crystals diffract $\mathrm{X}$-rays to a resolution of $2.0 \AA$ or greater. Considering all these advantages, the lactoglobulin variants L39Y, L39K, I56F, L58F, F105L, F105A, and M107L (Fig. 1) were co-crystallized with tetracaine in a series of experiments. Good quality crystals were obtained for most of the mutants and their structure was solved and refined with maximum resolution in the range of 2.1-1.8 $\AA$ (except for L39K, Table S2 at https://ojs.ptbioch.edu.pl/index.php/abp/). Careful investigation of the Fourier maps enabled to identify the electron density in the $\beta$-barrel (Fig. S4 at https://ojs. ptbioch.edu.pl/index.php/abp/) with the shape and dimensions corresponding perfectly to tetracaine in only two mutants: L58F and M107L. In these variants, tetracaine was bound in the way similar to that observed in natural lactoglobulin (Loch et al., 2015a) (Fig. 2). This is not surprising, because the binding pocket in both mutants has an elongated shape similar to the one present in WT protein. In the M107L variant, a short 4-carbon long aliphatic chain of TET is located in the bottom part of the binding pocket, the aromatic ring is placed in the middle/upper part near residues Val41 and Ile84, while a polar fragment possessing tertiary amine was found at 

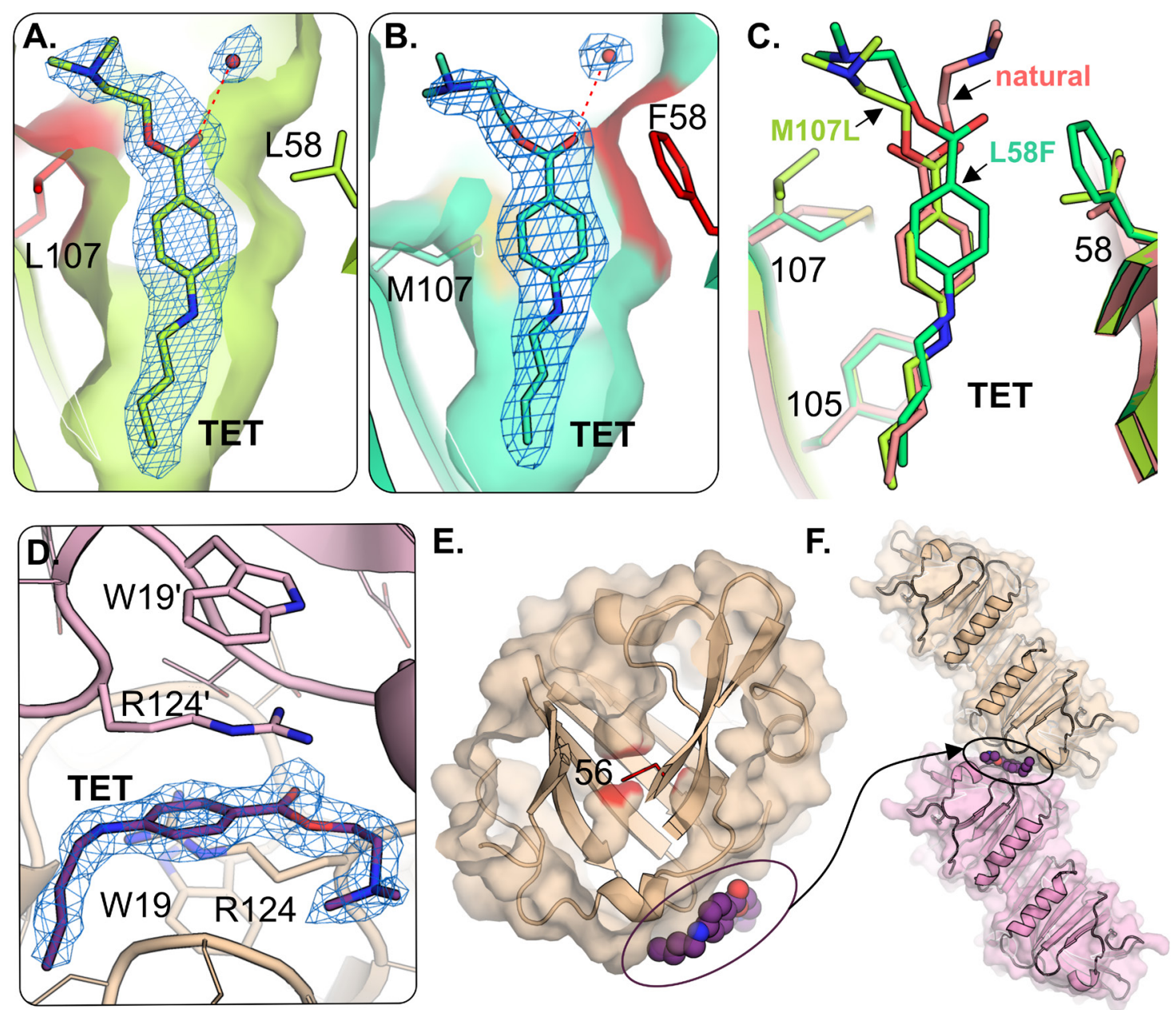

E.
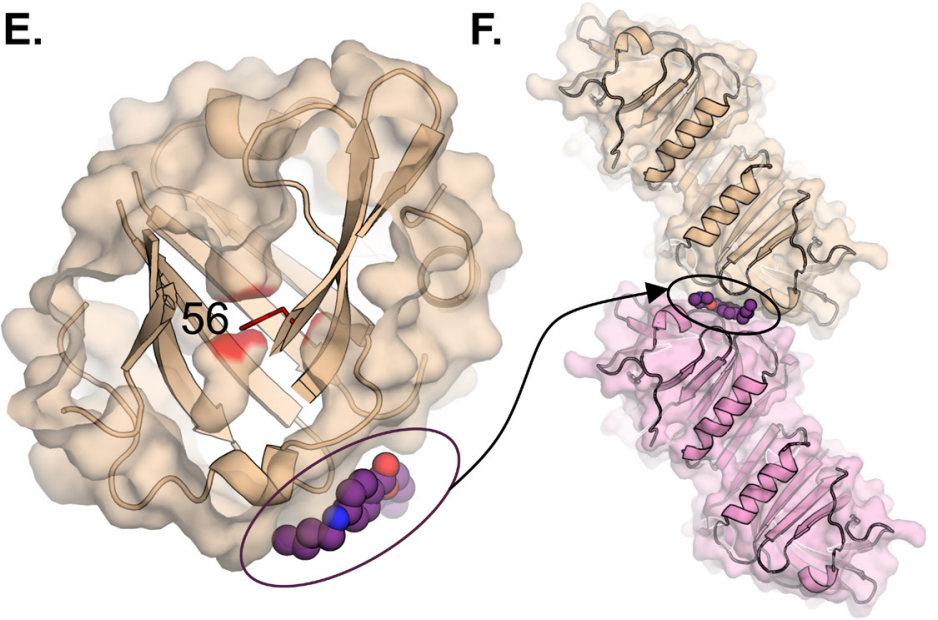

Figure 2. Interactions of tetracaine with the new lactoglobulin variants.

TET bound in $\beta$-barrel of (A) M107L and (B) L58F mutant. (C) Superposition of M107L (light green), L58F (green) and natural lactoglobulin (PDB ID: 4YOP, light pink). (D) TET bound on the surface of I56F variant. (E) The binding pocket shape in I56F mutant and TET binding site on I56F surface. (F) A single TET molecule trapped between two I56F dimers in the crystalline phase. All 2FoFc maps are shown at $1.00 \sigma$ level (omit maps calculated for ligands are presented in Fig. S4 at https://ojs.ptbioch.edu.pl/index.php/abp).

the vicinity of the EF loop, close to Asn90. Ligand was held in position by hydrophobic contacts with protein residues, while its polar part made hydrogen bonds to water molecules (Fig. 2).

In the crystal structure of the L58F variant, the ligand binding site was the same as in the natural BLG, however, due to the presence of a large phenylalanine side chain, the tetracaine position was shifted by about $1 \AA$ towards the $\beta$-barrel entrance (Fig. 2C). An electron density corresponding to the tetracaine molecule was also identified in the I56F variant (Fig. S4 at https:// ojs.ptbioch.edu.pl/index.php/abp/), however, not in the $\beta$-barrel but on the protein surface (Fig 2). Crystals of this variant had unusual orthorhombic symmetry $P 2_{1} 2_{1} 2_{1}$ (Table S2 at https://ojs.ptbioch.edu.pl/index.php/abp/) with protein dimer in the asymmetric unit. The binding pocket in the I56F variant (Bonarek et al., 2020) and its derivatives I56F/L39A and I56F/L39A/M107F (Loch et al., 2018) has a permanently reduced length. The large side chain of phenylalanine in position 56 prevents aliphatic ligands and tetracaine from binding in the modified binding pocket. Tetracaine was found on the protein surface in the small cavity formed between two protein molecules, next to the Arg124 from chain A and Arg124' from chain B' of the symmetry-related molecule (Fig. 2).
This observation is in good agreement with in silico predictions, indicating that binding sites other than $\beta$-barrel, may include (1) a hydrophobic pocket close to dimer interface in a groove between the $\alpha$-helix and the $\beta$-barrel (Yang et al., 2007; Domínguez-Ramírez et al., 2013) or (2) the outer surface near Trp19 and Arg124 (Sahihi et al., 2013; Liu et al., 2017; Xu et al., 2019). It is highly probable that different polar aromatic compounds, e.g. p-nitrophenyl phosphate, 5-fluorocytosine or ellipticine, can bind to this second site (Sahihi et al., 2013).

Although presented here crystal structure of I56F variant in complex with tetracaine is the first crystallographic evidence of a new binding site on the BLG surface near Arg124 and Trp19, this site requires two BLG molecules and is available only in the crystalline phase. Nevertheless, based on spectroscopic studies, it was proposed that some aromatic compounds were bound at a similar location (Liang \& Subirade, 2012; Xu et al., 2019). In the presence of TET, the molecular packing in crystals of the I56F variant was different than that observed for other BLG mutants. Mutation I56F promoted a small shifts of atoms in the entire molecule of I56F dimer in relation to WT dimer (PDB ID: 6QI6, r.m.s.d. $0.68 \AA$ ). These shifts are especially visible in the region of the $\beta$-strands B, C and D, which are located in close neigh- 
borhood of the TET binding site (Fig. S5 at https://ojs. ptbioch.edu.pl/index.php/abp/).

The $\mathrm{I} 6 \mathrm{~F}$ mutation seems to be the crucial factor for these changes as the crystal structure of another variant with reduced binding pocket size, the F105L, not possessing TET in both the $\beta$-barrel and on the protein surface, showed typical trigonal symmetry (Bonarek et al., 2020). X-ray diffraction data collected for F105L crystals obtained in two independent co-crystallization experiments always showed similar results: only small peaks of the electron density, interpreted as cryoprotectant molecules (glycerol), were found on the Fourier maps in the $\beta$-barrel (Fig. S3 at https://ojs.ptbioch.edu.pl/index.php/ $\mathrm{abp} /$ ). These observations indicate that the relatively flexible binding pocket in F105L is too small to accommodate the rigid TET molecule, although it was able to accommodate the fatty acid in the bent conformation (Bonarek et al., 2020).

The co-crystallization of TET with L39Y, L39K, and F105A variants, resulted in the growth of good-quality trigonal crystals. The electron density maps revealed in all these structures the presence of elongated electron density in the $\beta$-barrel (Fig. S3 at https://ojs.ptbioch. edu.pl/index.php/abp/). Such a density is typical for endogenous fatty acid blocking the binding pocket. These observations indicate that TET is not able to compete with endogenous fatty acids and displace them from the $\beta$-barrel. As these structures are almost identical to those obtained in the absence of ligand, we decided to include in this work the structures of L39K and F105A crystallized without ligand and structures of L39Y and F105L obtained in the presence of TET, as these structures have better resolution and overall quality than those previously deposited in the PDB (ID: 6QI7 and 6XVE).

\section{CONCLUSIONS}

X-ray crystallography was used to test the binding of the model ligand, tetracaine, to several BLG variants. High quality electron density maps allowed to unambiguously identify the type of a ligand bound in the $\beta$-barrel or at the protein surface. According to the results of the crystal structure analysis, mutants can be divided into four groups: [1] capable of binding TET in the $\beta$-barrel in a manner similar to natural protein (L58F, M107L); [2] capable of accommodating tetracaine on the protein surface (I56F); [3] unable to bind TET (F105L) and [4] variants with a binding pocket blocked by endogenous fatty acids (L39K, L39Y, F105A). The obtained results have been compared with the previously published (Bonarek et al., 2020) binding properties of BLG variants and are summarized in Table S3 (at https://ojs.ptbioch.edu. $\mathrm{pl} /$ index.php/abp/).

Of the seven variants analyzed (Table S3 at https:// ojs.ptbioch.edu.pl/index.php/abp/), in three cases, L39K, L39Y, and F105A, the binding pocket was blocked by endogenous fatty acid. In two other variants, L58F and M107F, both the fatty acid and tetracaine were bound in the binding pocket retaining its elongated shape. The significant differences were observed for two variants, I56F and F105L, with reduced length of the binding pocket. The $\mathrm{I} 56 \mathrm{~F}$ variant did not bind fatty acid or tetracaine in the $\beta$-barrel, but the tetracaine was found on the surface in the cavity formed between two protein molecules. This unusual ligand binding was accompanied by a different crystal symmetry than that observed for other variants. In the crystal structure of the F105L variant, the fatty acid was bound in the $\beta$-barrel in a bent conformation (Bonarek et al., 2020). Such a conformation is not accessible for the tetracaine molecule and that made it impossible to bind in the $\beta$-barrel.

It can be concluded that for tetracaine binding, the shape of the binding pocket seems to be a more important factor than the substitutions influencing the number of protein-ligand interactions in the $\beta$-barrel.

\section{Acknowledgements}

Authors would like to thank Kinga Kaczor, Ilona Łazińska, and Mateusz Gotkowski for participation in the protein expression, purification, and crystallization.

\section{REFERENCES}

Bonarek P, Loch JI, Tworzydło M, Cooper DR, Milto K, Wróbel P, Kurpiewska K, Lewiński K (2020) Structure-based design approach to rational site-directed mutagenesis of $\beta$-lactoglobulin. I Struct Biol 210: 107493. https://doi.org/10.1016/j.jsb.2020.107493

Deuschle FC, Ilyukhina E, Skerra A (2020) Anticalin ${ }^{\circledR}$ proteins: from bench to bedside. Expert Opin Biol Ther 1-10. https://doi.org/10.10 80/14712598.2021.1839046

Domínguez-Ramírez L, Del Moral-Ramírez E, Cortes-Hernández P, García-Garibay M, Jiménez-Guzmán J (2013) ß-lactoglobulin's conformational requirements for ligand binding at the calyx and the dimer interphase: a flexible docking study. PLoS One 8: e79530. https://doi.org/10.1371/journal.pone.0079530.

Emsley P, Lohkamp B, Scott WG, Cowtan K (2010) Features and development of Coot. Acta Crystallogr D Biol Crystallogr 66: 486-501. https://doi.org/10.1107/S0907444910007493

Gasteiger E, Hoogland C, Gattiker A, Duvaud S, Wilkins MR, Appel RD, Bairoch A (2005) Protein Identification and Analysis Tools on the ExPASy Server. In The Proteomics Protocols Handbook, pp 571-607. Totowa, NJ: Humana Press

Keedy DA, Hill ZB, Biel JT, Kang E, Rettenmaier TJ, Brandão-Neto J, Pearce NM, von Delft F, Wells JA, Fraser JS (2018) An expanded allosteric network in PTP1B by multitemperature crystallography, fragment screening, and covalent tethering. Elife 7: 1-36. https:// doi.org/10.7554/eLife.36307

Liang L, Subirade M (2012) Study of the acid and thermal stability of $\beta$-lactoglobulin-ligand complexes using fluorescence quenching. Food Chem 132: 2023-2029. https://doi.org/10.1016/j.foodchem.2011.12.043

Liu J, Jiang L, Zhang Y, Du Z, Qiu X, Kong L, Zhang H (2017) Binding behaviors and structural characteristics of ternary complexes of $\beta$-lactoglobulin, curcumin, and fatty acids. RSC Adv 7: 4596045967. https://doi.org/10.1039/c7ra09012a

Loch J, Polit A, Górecki A, Bonarek P, Kurpiewska K, DziedzickaWasylewska M, Lewiński K (2011) Two modes of fatty acid binding to bovine $\beta$-lactoglobulin - crystallographic and spectroscopic studies. J Mol Recognit 24: 341-349. https://doi.org/10.1002/jmr.1084

Loch JI, Bonarek P, Polit A, Jabłoński M, Czub M, Ye X, Lewiński K (2015a) $\beta$-Lactoglobulin interactions with local anaesthetic drugs - Crystallographic and calorimetric studies. Int J Biol Macromol 80: 87-94. https://doi.org/10.1016/j.ijbiomac.2015.06.013

Loch JI, Bonarek P, Polit A, Riès D, Dziedzicka-Wasylewska M, Lewiński K (2013a) Binding of 18-carbon unsaturated fatty acids to bovine $\beta$-lactoglobulin - Structural and thermodynamic studies. Int J Biol Macromol 57: 226-231. https://doi.org/10.1016/j.ijbiomac.2013.03.021

Loch JI, Bonarek P, Polit A, Świątek S, Czub M, Ludwikowska M, Lewiński K (2015b) Conformational variability of goat $\beta$-lactoglobulin: Crystallographic and thermodynamic studies. Int J Biol Macromol 72: 1283-1291. https://doi.org/10.1016/J.IJBIOMAC.2014.10.031

Loch JI, Bonarek P, Polit A, Swiątek Ś, Dziedzicka-Wasylewska M, Lewiński $K$ (2013b) The differences in binding 12-carbon aliphatic ligands by bovine $\beta$-lactoglobulin isoform $\mathrm{A}$ and $\mathrm{B}$ studied by isothermal titration calorimetry and X-ray crystallography. J Mol Recognit 26: 357-367. https://doi.org/10.1002/jmr.2280

Loch JI, Bonarek P, Tworzydło M, Lazińska I, Szydłowska J, Lipowska J, Rzęsikowska K, Lewiński K (2018) The engineered $\beta$-lactoglobulin with complementarity to the chlorpromazine chiral conformers. Int J Biol Macromol 114: 85-96. https://doi. org/10.1016/J.IJBIOMAC.2018.03.074

Loch JI, Bonarek P, Tworzydło M, Polit A, Hawro B, Lach A, Ludwin E, Lewiński K (2016) Engineered $\beta$-lactoglobulin produced in E. coli: Purification, biophysical and structural characterisation. Mol Biotechnol 58: 605-618. https://doi.org/10.1007/s12033-016-9960-z

Loch JI, Molenda M, Kopeć M, Swiątek S, Lewiński K (2014) Structure of two crystal forms of sheep $\beta$-lactoglobulin with EF-loop 
in closed conformation. Biopolymers 101: 886-894. https://doi. org/10.1002/bip.22471

Loch JI, Polit A, Bonarek P, Olszewska D, Kurpiewska K, DziedzickaWasylewska M, Lewiński K (2012) Structural and thermodynamic studies of binding saturated fatty acids to bovine $\beta$-lactoglobulin. Int J Biol Macromol 50: 1095-1102. https://doi.org/10.1016/J.IJBIOMAC.2012.03.002

McCoy AJ, Grosse-Kunstleve RW, Adams PD, Winn MD, Storoni LC, Read RJ (2007) Phaser crystallographic software. J Appl Crystallogr 40: 658-674. https://doi.org/10.1107/S0021889807021206

Murshudov GN, Skubák P, Lebedev AA, Pannu NS, Steiner RA, Nicholls RA, Winn MD, Long F, Vagin AA (2011) REFMAC5 for the refinement of macromolecular crystal structures. Acta Crystallogr D Biol Crystallogr 67: 355-367. https://doi.org/10.1107/ S0907444911001314

Rothe C, Skerra A (2018) Anticalin ${ }^{\circledR}$ proteins as therapeutic agents in human diseases. BioDrugs 32: 233-243. https://doi.org/10.1007/ s40259-018-0278-1

Sahihi M, Ghayeb Y, Khalegh Bordbar A (2013) Interaction of $\beta$-lactoglobulin with resveratrol: Molecular docking and molecular dynamics simulation studies. Chem Biochem Eng Q 27: 417-422
Sreerama N, Woody RW (2000) Estimation of protein secondary structure from circular dichroism spectra: comparison of CONTIN, SELCON, and CDSSTR methods with an expanded reference set. Anal Biochem 287: 252-260. https://doi.org/10.1006/abio.2000.4880

Winn MD, Ballard CC, Cowtan KD, Dodson EJ, Emsley P, Evans PR, Keegan RM, Krissinel EB, Leslie AGW, McCoy A, McNicholas SJ, Murshudov GN, Pannu NS, Potterton EA, Powell HR, Read RJ, Vagin A, Wilson KS (2011) Overview of the CCP4 suite and current developments. Acta Crystallogr D Biol Crystallogr 67: 235-242. https://doi.org/10.1107/S0907444910045749

Xu H, Lu Y, Zhang T, Liu K, Liu L, He Z, Xu B, Wu X (2019) Characterization of binding interactions of anthraquinones and bovine $\beta$-lactoglobulin. Food Chem 281: 28-35. https://doi.org/10.1016/j. foodchem.2018.12.077

Yang M-C, Guan H-H, Liu M-Y, Lin Y-H, Yang J-M, Chen W-L, Chen C-J, Mao SJT (2007) Crystal structure of a secondary vitamin D3 binding site of milk $\beta$-lactoglobulin. Proteins Struct Funct Bioinforma 71: 1197-1210. https://doi.org/10.1002/prot.21811 